\section{Men's role in violence against women in disasters: studies in Iran and Australia}

\section{SUBMITTED \\ 5 October 2021}

\section{ACCEPTED}

26 November 2021

\section{DOI}

www.doi.org/10.47389/37.1.66

\section{(c) 1 (1) (9)}

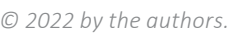
License Australian Institute for Disaster Resilience, Melbourne, Australia. This is an open access article distributed under the terms and conditions of the Creative Commons Attribution (CC BY) license (https:// creativecommons.org/ licenses/by/4.0/).

\section{Introduction}

Two studies of men's violence against women after floods and earthquakes in Iran (Sohrabizadeh 2016) and bushfires in Australia (Parkinson 2015) show remarkable similarities. This article details author observations and compares the findings and the complexities faced by the researchers in conducting these studies. The common standpoint of both research projects was that violence against women is a violation of human rights and a barrier to gender equality. Violence against women is defined as: 'Any act of gender-based violence that results in, or is likely to result in, physical, sexual, or psychological harm or suffering to women, including threats of such acts, coercion, or arbitrary deprivation of liberty, whether occurring in public or in private life' (United Nations General Assembly 1993). Violence against women and girls is exacerbated after disasters and endangers their health and security (International Recovery Platform 2005). According to Parkinson (in press), there were at least 50 journal articles during the period 1993 to 2020 on increased violence against women in disasters in 14 different countries, in addition to 16 multi-country studies. The disasters were as diverse as the Mt. Pinatubo eruption in the Philippines in 1991 (IASC 2005), Hurricane Katrina in the US in 2005 (e.g. Enarson 2012, Schumacher et al. 2010), the Sichuan earthquake in 2008 (Chan \& Zhang 2011), climate change in flood-prone Sindh in Pakistan (Memon 2020) and COVID-19 in many countries during 2020 (UN Women 2020). It appears that the type of disaster and the relative wealth of countries has little to do with the increase in violence against women that accompanies disasters (Lee 2018). Comparing cases of violence against women in different contexts and sharing the experiences provides lessons for preventing violence during future events. This paper contributes by comparing 2 very different countries. While both studies (Parkinson 2015, Sohrabizadeh 2016) had research objectives, the objective of this paper is to compare the findings of these research papers and outline the difficulties faced in conducting these studies in these countries.

\section{Abstract}

Sexual violence is largely absent from studies on violence against women in disasters. The role of men in perpetrating violence against women is overlooked or excused and women are usually blamed in both countries. A review of 2 studies of men's violence against women after floods and earthquakes in Iran and bushfires in Australia show remarkable similarities. Although cultural contexts and the way gender inequality is established and demonstrated are different, these studies reveal unexpected parallels. The context of disaster lays it bare. Participants of both studies were disaster-affected people in Iran and Australia who revealed the taboos that prevent women speaking of violence that is exacerbated in a disaster context. Men play important roles in preventing and responding to violence against women as the result of their responsibilities and positions at the household and community levels. The objective of this paper was to compare the findings from these studies and consider the difficulties faced in conducting studies related to the roles of men and women roles during and after disaster events. 


\section{Methodology}

\section{Design}

The methodologies used in the 2 studies were almost identical. Both studies were conducted using a qualitative research approach. A qualitative content analysis was taken in Iran (Graneheim \& Lundman 2004) and Grounded Theory (Glaser \& Strauss 1967) in Australia. This study was approved by the ethics committee of Shahid Beheshti University of Medical Sciences, Tehran, Iran (\#IR.SBMU.PHNS.REC.1400.095) and Monash University Human Research Ethics Committee (\# CF10/04482010000209).

\section{Setting and participants}

The Iranian study included field observations in 3 affected regions of East Azerbaijan, Bushehr and Mazandaran. Affected women, as well as key informants (experienced scholars and experts), were interviewed in Iran using a purposive sampling method. While field observations were not formally noted in the Australian methodology, it nevertheless formed part of data gathering as interviews with women were preceded by visits to the bushfire-affected communities of Kinglake, Marysville and Flowerdale, and interviews and focus groups were conducted with 47 recovery workers. Data saturation was obtained after 15 interviews in the Iranian study and 30 interviews in the Australian study. Data were gathered through face-to-face, in-depth interviews in Iran and in-depth, semi-structured interviews in Australia. All interviews were audio recorded, transcribed and confirmed by the participants.

\section{Data analysis}

Data collection and data analysis were conducted simultaneously in both settings. A qualitative content analysis using the Graneheim approach was applied for analysing data in the Iranian study. In Australia, data analysis was conducted based on Grounded Theory and assisted by NVivo software. Both analytic techniques focus strongly on data coding and an inductive approach to enhance the rigour of the findings and to allow the findings and conclusions to emerge from the women's accounts.

\section{Study limitations and resistance to research}

Researchers in both countries faced significant barriers. In Australia, people involved in the post-Black Saturday recovery expressed concerns about the research. Some recovery workers suggested removing the word 'violence' from the research recruitment flyer and others warned that women might not respond. A year earlier, ethics approval was sought to interview police and, after a lengthy process, advice was given that the research could only been done if it was not about women and not about violence. Some recovery workers vehemently rejected the notion that men's violence in the home after Black Saturday was a problem, and one worker after another spoke of the heightened sensitivities of post-disaster circumstances. Many warned against adding to the burden on vulnerable communities. The attempt was to shut the research down-to silence the researchers as well as the women. In both countries, some women who participated were anxious about potential ramifications, as complete confidentiality could not be guaranteed. In small towns in Australia, for example, many people knew of experiences of others. Venues for interviews and addresses for transcript checks had to be carefully considered. Some women withdrew their accounts or large parts of their transcripts because of this unavoidable risk.

This resistance to accepting the research findings of increased violence against women in disasters extended to disseminating the research. The first public presentations of the Australian findings in forums and conferences faced objections from police and from community members 'defending' and 'standing up for' men in their communities.

In Iran, the research subject is also a culturally sensitive issue. This made the process of data collection and analysis very difficult. Receiving ethics approval was equally problematic. Talking about experiences of violence is not desirable in Iranian communities, especially after disaster events.

\section{Findings}

\section{The ways gender inequality is established and demonstrated}

Gender inequality is premised on men's violence against women, on a persistent pay gap that sees women paid less than men and on a predominance of men in all levels of government as well as executive levels in the private sector. The senior roles that men fulfil is evident in the clothes they wear; a suit and tie denote authority as do emergency services uniforms. The predominance-and expectation-of women holding unpaid caring roles has a life-long impact on financial assets held by women (Australian Human Rights Commission 2013). Poverty for women, as single parents or in retirement, far outstrips that of men. As a country, Australia seems unwilling to address this. Australia's ranking on the World Economic Forum's Global Gender Gap Report (2021) continues to fall, currently sitting at 50 of 156 countries. Gender inequality in Iran is worse and it is ranked at 150 out of 156 countries. The gender gap is reported in political, economic and education aspects (World Economic Forum 2021). Given that Iran is a highly disaster-prone country, gender inequality can be exacerbated after disasters, and this put women and girls in danger of being violated by men.

\section{Parallels in violence against women for both countries}

These studies were the first research projects to focus on violence against women in disasters in both countries. A critical finding was that violence against women increased after earthquakes and floods in Iran, and bushfires in Australia. Prior to publication of Sohrabizadeh's research (2016) and Parkinson \& Zara's research (2011), there were no published investigations indicating the lack of attention to violence against women in emergency management and planning. In Iran, 2 themes were extracted of domestic violence and violence within communities. 
The first theme included 3 categories: physical, psychological and sexual violence. Psychological violence and sexual harassment were 2 categories of violence within the community concept. The Australian research echoed these themes.

Parkinson \& Zara (2011) described occasions of community violence at events such as community recovery meetings and community dining, as well as in local streets. Physical violence by men against women was described in both research reports. In Iran, some women suffered from physical abuse and violence carried out by their partners, fathers and sons. These aggressive behaviours affected the health and coping capacities of women during the recovery phase. Participants stated that the mental distress of men caused by the disaster event triggered changed behaviours and reactions and played out as forms of physical violence against women and girls (Sohrabizadeh 2016a). In Australia, the women interviewed linked their partner's new or increased levels of violence to the men's experiences in the 2009 bushfires. Several spoke compassionately about their partner despite his violence because of what he had been through.

Psychological violence was purposely not foregrounded in the Australian research. Instead, researchers alerted authorities and the emergency management sector to the criminality of men's (physical) domestic violence as described by the respondents. Nevertheless, the narratives of the participants indicated that psychological violence was also used by men after Black Saturday in 2009. It was apparent in men blaming women and seeking to control their activities as well as 'gaslighting'1 women about what had happened during the disaster. In Iran, post-disaster psychological violence occurred in forms of controlling and insulting women, denying women's rights to be independent and through men threatening to divorce the wife or leave the home. In addition, verbal violence was reported by women and girls. Unlike Australia, in Iran, forced marriages of girls was an important barrier to leaving marriages for teenage girls who were prevented from continuing their education in high schools (Sohrabizadeh 2016b). One Iranian participant stated:

I am really eager to go to a high school for getting my diploma and continue my academic education in a college. Unfortunately, my parents cannot afford the costs of high school after the earthquake and I have to get married or stay at home. (p.10)

Sohrabizadeh (2016b) noted that sexual violence against women is largely absent from disaster studies. This also applies in Australia as none of the women spoke of sexual violence, which is not to say that they were not experiencing it. The taboo that prevents women speaking of violence is exacerbated in a disaster context. In Iran, affected women who lost their children or relatives were blamed for intimate partner violence. Women were shocked and depressed when losing a loved one and thus, they did not intend to have sexual relationships with their husbands. Some men ignored their partner's unwillingness and perpetrated acts of sexual violence against their spouses after disasters.
Australian research into partner rape (Parkinson 2017) concluded that men's sense of entitlement to sex with women is deeply entrenched and it follows that is rare for women to report intimate partner sexual violence because of shame and fear of retaliation (McOrmond-Plummer, Easteal \& Levy-Peck 2014; Parkinson 2009, 2010; Sohrabizadeh 2016a; Sohrabizadeh 2014). However, when participants are specifically recruited to speak about sexual violence, they do. This confirms the absolute necessity to 'name the problem' and not use euphemisms. In retrospect, the Australian study could have included a question in semi-structured interviews about sexual violence to allow women to speak about this aspect of violence against them. There is deep shame attached to sexual violence and this is evident in the cultural contexts for both Australia and Iran. Both cultures attach blame to women who experience men's sexual violence. This is another reason why women don't report it.

\section{Women are blamed}

Women are blamed for men's physical violence against them. The Australian research (Parkinson 2017) draws on women's accounts where they were accused of not being a good enough wife, not supporting their husband or partner, not giving him enough time. The expectation that women put their own needs last, even to the point of tolerating violence from the man in their home, was conveyed clearly to women by family members, health professionals and police. Women had limited to no options to turn for help in the aftermath of the 2009 bushfires. Since that time, the lack of data confirms that there is still resistance to hearing of men's violence in a bushfire context. While media and grey literature focus on anticipated spikes (e.g. Gleeson 2020), to date, there is no qualitative or quantitative published research on domestic violence after the summer bushfires in 2019-20 in Australia, nor after earthquakes and floods in Iran.

\section{The privileging of men}

Men, in general, are privileged in patriarchal societies. The level of privilege enjoyed differs depending on class, age, race and ethnicity and different groups of men enjoy different levels of the 'patriarchal dividend' (Pease 2010). This offers insight for why violence against women is largely overlooked in emergency management planning. In Australia, firefighters are iconic. They have community gratitude and admiration and, in 2021, ranked fourth among the most respected of occupations in surveys, including by Reader's Digest. ${ }^{2}$ Iran is a male-dominant country focusing on men's abilities and skills in disaster management. Women have been perceived as passive and helpless victims waiting for relief by capable men in disaster-affected regions. This can explain why women's needs and challenges, especially violence against women, have not been adequately considered in previous disasters. In Iran, some men prefer to believe that women's involvement in emergency and disaster management

1. In See what you made me do, Jess Hill describes 'gaslighting' as when an abuser knowingly denies, fabricates and manipulates situations to make a partner doubt their memory or perception' (p.26).

2. The most trusted professions in Australia. At: www.readersdigest.com.au/truestories-lifestyle/work/the-most-trusted-professions-in-australia. 
would be a barrier to meeting their goals and this is why women should stay home and take care of family members (Sohrabizadeh 2014). A woman who was economically affected by earthquake stated:

There are only a few employment opportunities for women in the disaster-stricken regions. There are not any equal job opportunities for women. Men don't imagine that women need to have jobs and only mentioned the availability of economic support at the relief foundations. (p.12)

\section{Perpetrating violence is overlooked or excused}

In 2020 in Australia, discrimination and sexual harassment and assault in the workplace reached media saturation and finally seemed to have received the attention of governments. Historically, there has been reluctance to address men's violence against women, particularly if they held high occupational status. Politicians and men in powerful positions are unlikely to face censure for violence against women as attested by the litany of reports in recent years (e.g. Australian Human Rights Commission 2021, VEOHRC 2020). The respected status of firefighters leads to even greater reticence to hear from women about the violence they experience post-bushfires. 'Nobody wants to hear that men who embody the spirit of resilient and heroic Australia are violent towards their families' (Parkinson 2015, p.142). Equally, there was reluctance to implicate men of standing within the community, wealthy men, policemen as well as suffering men. Men who were traumatised or now unemployed as a result of their disaster experience.

The pandemic during 2020 was a period in Australia when women's experience of violence in the home was recognised as a 'shadow epidemic' and a reason for national soul-searching and funding. This willingness to call out increased domestic violence in lockdowns is in stark contrast to the bushfire context. It clarifies the nationwide reluctance to implicate career and volunteer firefighters and community 'heroes'. What is it about the Australian culture that excuses men and tolerates violence against women at the rate of one in 3 women experiencing violence in their lifetime, and one women killed every week by her intimate partner (Cullen et al. 2019)?

The role of men in perpetrating violence against women has similarly been overlooked in Iran. Cases of violence against women are not regularly reported by organisations and the public are not formally informed about pre-and post-disaster status of violence against women in Iran. Excusing men's roles in violence against women is rooted in Iranian patriarchal culture and in the way girls grow up. Women do not have enough information about types of violence and consider men's violating behaviours as a routine part of their lives (Sohrabizadeh 2016a, Sohrabizadeh 2014).

The findings by Sohrabizadeh (2014) echo those of Parkinson \& Zara (2011) in attributing the excusing of men's violence against women to patriarchal cultures. It is only in recent decades that authorities in Australia have begun to question men's privilege. In 2021, education to girls and boys about 'consent' was introduced, along with ensuring accountability of people and systems (such as police and employers) to respond to and prevent physical and sexual violence against women.

\section{Ways disaster exposes or increases violence against women}

During disaster response and in the aftermath, there is pressure on women to stay silent about their partner's violence. However, at the same time, the chaos of disaster, loss of privacy and increased sharing of circumstances can increase the potential for, and can expose, violence in the home. Around the world, emergency and disaster researchers report that men's violence against women after disasters is linked to stress, grief and loss, trauma, homelessness, unemployment, disruption to support networks, financial problems and bureaucratic hurdles (e.g. Enarson, Fothergill \& Peek 2017). Disasters are a catalyst for change and contribute to the evolution of social systems (Quarantelli 1994). That change can be progressive as Parkinson (2019) asserts:

The aftermath of Black Saturday presents Australians with the opportunity to see how deeply embedded misogyny is and how fragile our attempts to criminalise domestic violence and hold violent men accountable. (p.2357)

In Iran, women suffer from a lack of knowledge about the right to live without violence (Sohrabizadeh 2016a). However, disasters aggravate violence against women and this contributes to mental and physical disorders for affected women. It can be concluded that important and progressive change can be driven by disasters, breaking the cultural taboo of violence against women in Iran. This may take place slowly, but disasters may be a catalyst for this positive change. While women need to be informed and trained about prevention and response to violated behaviours during pre and post-disaster phases, men also have an important role in preventing such violence.

\section{Alcohol and drug abuse}

A cultural difference is the role of alcohol and drug abuse in Australia compared to Iran, where drinking alcohol is forbidden due to the Islamic rules. Intoxicated people are punished physically and economically, thus, alcohol abuse is not reported formally. Disaster-affected men cannot resort to drinking in Iran. However, men use drugs as a pain killer and an increase of drug abuse among affected men has been reported by some authors (Farhoudian et al. 2006, Rahimi Movaghar et al. 2007). Although formal reports do not include the role of drug abuse in increasing violence against women in Iran, current evidence is that violence against women can be exacerbated due to using drugs in disaster-stricken regions. After the Australian Black Saturday bushfires in 2009, abuse of alcohol was widespread. Many communities objected to the use of pubs as venues for community meetings, advertising for alcohol at family events and the inclusion of alcohol in community get-togethers. The immediate aftermath of the bushfires was likened to a 'wild-west' environment, with men getting together in the street to drink in 
the absence of the tempering influence of women and children (Parkinson \& Zara 2011). One participant said:

The men were really started to drink. My friend was having people rock up at the door at all times of the day. They were drinking in the street. They were getting together as blokes. (p.111)

That study concluded:

It appeared that alcohol and drug use increased postfire as people struggled to cope with the wholesale destruction of property and life and ongoing frustrations. Workers described many people self-medicating with alcohol to escape the pain and they linked the increased alcohol to men's use of violence ${ }^{3}$... Alcohol is very much a part of the Australian culture and some workers viewed its use as an understandable, if not legitimate, response to the fires. (Parkinson \& Zara 2011, pp.167-168).

\section{Men's roles in preventing or responding to violence against women in disasters}

In Iran and Australia, there have been considerable efforts to prevent violence against women over the past 40 years. Two approaches have been followed:

- focusing on violence against women prevention before it happens

- involving men in violence against women mitigation and prevention.

Men, as the main perpetrators, are increasingly acknowledged as important partners in reducing violence against women. In Iran, as a male-dominant country with a huge gender gap, men play important roles in responding to violence against women and girls. Furthermore, men's decision-making and economic dominance in the family and the community is an important predictor of violence against women (Sohrabizadeh 2016a).

In Iran and Australia, men have more access to resources and are active in management and policymaking positions than are women. Men can allocate resources and make decisions to mitigate post-disaster violence against women at local, regional and national levels. Men must be engaged in community-based interventions addressing violence against women in disasters. For example, men can participate in education and training programs and social campaigns for violence against women prevention. Their roles as policymakers, advocates and activists can improve prevention and build gender equality (Berkowitz 2004, Flood 2010). In Iran, the strong capacity of the health care network can facilitate the involvement of men and boys in community-based interventions to reduce violence against women. This wide network can provide training programs in violence against women prevention for men and boys living in

3. Although the domestic violence literature identifies the strong link between violence and alcohol (Abramsky et al. 2011, Foran \& O'Leary 2008, Livingston 2011), there are concerns that alcohol be misconstrued as causing the violence, thereby reducing perpetrator responsibility for their violence and failing to target its real causes' (Braaf 2012, p.1). rural and urban regions. As men predominantly hold the key positions of responsibility at household and community levels in Iran, they can lead the change needed for violence against women prevention and management in disasters.

\section{Conclusion}

Sharing the experiences of violence against women postdisaster in distinctive socio-cultural contexts and considering the similarities and differences focusing on men's roles provide valuable insights. Collecting and sharing these experiences could successfully reduce and prevent violence against women in disasters. For example, education for boys about how respecting the rights of girls and women is important to achieve a safe community without violence. This could be conducted through public education and building cultures of gender equality.

The predominance in Iran and Australia of men in emergency management roles and women in violence against women prevention work must be urgently addressed. Men can influence other men and can use that influence for positive change to reduce violence against women. In this way, women are not alone in progressing change. It is vital that women and men are involved in disaster response and recovery activities and that they work to eliminate violence.

It is equally vital that research into violence against women in disaster be continued and findings accepted, despite the sensitivity of this in disaster-affected communities. Women and children have the right to live free from violence in any circumstance.

\section{References}

Abramsky T, Watts CH, Garcia-Moreno C, Devries K, Kiss L, Ellsberg M, Jansen HAFM \& Heise L 2011, What factors are associated with recent intimate partner violence? Findings from the WHO multi-country study on women's health and domestic violence. Biomed Central Public Health, vol. 109, pp.1-17.

Austin DW 2008, Hyper-masculinity and disaster: Gender role construction in the wake of Hurricane Katrina. Paper presented at the American Sociological Association Annual Meeting, Sheraton Boston and the Boston Marriott Copley Place, MA. At: http://citation.allacademic.com/meta/p_mla_apa_research_ citation/2/4/1/5/3/p241530_index.html.

Australian Human Rights Commission 2021, Set the Standard: Report on the Independent Review into Commonwealth Parliamentary Workplaces. At: https://humanrights.gov.au/setstandard-2021.

Berkowitz AD 2004, Working with Men to Prevent Violence Against Women: An Overview (Part One). Applied Research Forum, pp.1-8.

Braaf R 2012, Elephant in the Room: Responding to alcohol misuse and domestic violence. Australian Domestic and Family Violence Clearinghouse Issues Paper, vol. 24. 
Australian Human Rights Commission 2013, Investing in care: Recognising and valuing those who care, Volume 1 Research Report, Australian Human Rights Commission, Sydney.

Chan K \& Zhang Y 2011, Female victimization and intimate partner violence after the May 12, 2008, Sichuan earthquake. Violence and Victims, vol. 26, no. 3, pp.364-376.

Cullen P, Vaughan G, Zhuoyang Li, Price J, Denis Y \& Sullivan E 2019, Counting Dead Women in Australia: An In-Depth Case Review of Femicide. Journal of Family Violence, vol. 34, no. 1, pp.1-8.

Enarson E 2012, Women confronting natural disaster: From vulnerability to resilience. Boulder, Colorado: Lynne Rienner Publishers.

Enarson E, Fothergill A \& Peek L 2017, Gender and Disaster: Foundations and New Directions for Research and Practice. In Handbook of Disaster Research (Handbooks of Sociology and Social Research, pp. 205-223. Cham: Springer International Publishing.

Farhoudian A, Rahimi Movaghar A, Rad Goodarzi R, Younesian M, Mohammadi MR 2006, Changes in the use of opioid drugs and available interventions in Bam during the first year after the earthquake. Hakim Journal, vol. 9, no. 1, pp.52-57. [In Persian]

Flood M 2010, Where Men Stand: Men's roles in ending violence against women. White Ribbon Foundation Report, No. 2.

Foran HM \& O'Leary KD 2008, Alcohol and intimate partner violence: A meta-analytic review. Clinical Psychology, vol. 28, no. 7, pp.1222-34.

Fordham M 2008, The intersection of gender and social class in disaster: Balancing resilience and vulnerability. In B. D. Phillips \& B. H. Morrow (Eds.), Women and disasters: From theory to practice, pp.75-98. Philadelphia, PA: International Research Committee on Disasters.

Glaser B \& Strauss A 1967, The Discovery of Grounded Theory: Strategies for Qualitative Research. Chicago: Aldine.

Gleeson H 2020, A new bushfire crisis is emerging as experts brace for an imminent surge in domestic violence. $A B C$ News. At: www.abc.net.au/news/2020-02-24/domestic-violenceanticipated-spike-bushfires-crisis/11980112.

Graneheim U \& Lundman B 2004, Qualitative content analysis in nursing research: concepts, procedures, and measures to achieve trustworthiness. Nurse Ed Today, vol. 24, no. 2, pp.105-112.

Hill J 2019, See what you made me do. Carlton: Black Inc. Schwartz Publishing.

IASC (Inter-Agency Standing Committee) 2005, Guidelines for Gender-based Violence Interventions in Humanitarian Settings Focusing on Prevention of and Response to Sexual Violence in Emergencies. At: www. unhcr.org/refworld/docid/439474c74.html.

International Recovery Platform 2005, Guidance Note on Recovery: Gender. At: www.wcdrr.org/wcdrrdata/uploads/854/ Guidance\%20note\%20on\%20recovery\%20-\%20Gender.pdf.
Lee A 2018, Rapid Review of Gender-based Violence and Natural Disasters. K. Khoshnood and D. Humphries, ProQuest Dissertations Publishing.

Livingston M 2011, A longitudinal analysis of alcohol outlet density and domestic violence. Addiction, vol. 106, pp.919-925.

McOrmond-Plummer L, Easteal P \& Levy-Peck J (Eds) 2014, Intimate Partner Sexual Violence: A Multidisciplinary Guide to Improving Services and Support for Survivors of Rape and Abuse. London: Jessica Kingsley Publishers.

Memon FS 2020, Climate Change and Violence Against Women: Study of A Flood-Affected Population in The Rural Area of Sindh, Pakistan. Pakistan Journal of Women's Studies: Alam-e-Niswan, vol. 27, no. 1, pp.65-85.

Parkinson D (In press). Gender-based Violence and Disasters. In Benouar, D. (Ed.), The Oxford Research Encyclopedia of Natural Hazard Science. Oxford University Press. doi:10.1093/ acrefore/9780199389407.013.390

Parkinson D 2009, Why partner rape is so invisible and why women don't report. DVIRC Quarterly, vol. 2, pp.14-15.

Parkinson D 2010, Supporting Victims Through the Legal Process. ACSSA Wrap No. 8. At: www.aifs.gov.au/acssa/pubs/wrap/wrap8/ w8.pdf.

Parkinson D 2015, Women's experience of violence in the aftermath of the Black Saturday bushfires. PhD Thesis, Monash University. At: https://figshare.com/articles/Women_s_ experience_of_violence_in_the_aftermath_of_the_Black_ Saturday_bushfires/4705114.

Parkinson D 2017, IPSV Perpetrators and Entitlement in McOrmond-Plummer L, Levy-Peck J \& Easteal P (Eds.). Perpetrators of Intimate Partner Sexual Violence. Oxford: Taylor \& Francis Books.

Parkinson D 2019, Investigating the Increase in Domestic Violence Post-disaster: An Australian Case Study. Journal of Interpersonal Violence, vol. 34, no. 11, pp.2333-62.

Parkinson D \& Zara C 2011, 'The way he tells it...' Relationships after Black Saturday, Wangaratta: Women's Health Goulburn North East. At: www.genderanddisaster.com.au/info-hub/research-resources/.

Pease B 2010, Undoing privilege: Unearned advantage in a divided world. London: Zed Books.

Quarantelli EL 1994, DRC Preliminary Paper 228: Draft of a sociological disaster research agenda for the future: Theoretical, methodological and empirical issues. Newark: Disaster Research Centre, University of Delaware.

Rahimi Movaghar A, Farhoudian A, Rad Goodarzi R, Sharifi V, Younesian M, Mohammadi MR 2007, The frequency of drug abuse among Bam earthquake survivors one year after the earthquake. Payesh Journal, vol. 6, no. 3, pp.209-217. [In Persian]

Schumacher J, Coffey S, Norris F, Tracy M, Clements K \& Galea S 2010, Intimate partner violence and Hurricane Katrina: predictors and associated mental health outcomes. Violence and Victims, vol. 25, no. 5, pp.588-603. 
M RESEARCH

Sohrabizadeh S 2016a, A Qualitative Study of Violence against Women after the Recent Disasters of Iran. Prehospital and Disaster Medicine, vol. 1, no. 4, pp.407-412.

Sohrabizadeh S 2016b, The Neglect of Women's Capacities in Disaster Management Systems in Iran: A Qualitative Study. Indian Journal of Gender Studies, vol. 23. no. 3, pp.467-480.

Sohrabizadeh S 2014, Exploring Gender Analysis Factors in Disaster Risk Management: The Case of Iran. PhD Thesis, Iran University of Medical Sciences. Tehran, Iran.

UN Women 2020, Impact of COVID-19 on violence against women and girls and service provision: UN Women rapid assessment and findings. At: www.unwomen.org/-/media/headquarters/ attachments/sections/library/publications/2020/impact-of-covid19-on-violence-against-women-and-girls-and-service-provisionen.pdf?/a=en\&vs=0.

United Nations General Assembly 1993, Declaration on the Elimination of Violence against Women. At: www.un.org/ documents/ga/res/48/a48r104.htm.

Victorian Equal Opportunity and Human Right Commission (VEOHRC) 2020, Independent review of Ambulance Victoria. At: www.humanrights.vic.gov.au/legal-and-policy/research-reviewsand-investigations/ambulance-victoria-review/about/.

World Economic Forum 2021, Global Gender Gap Report. At: www3.weforum.org/docs/WEF_GGGR_2021.pdf.

\section{About the authors}

Dr Sanaz Sohrabizadeh is Associate Professor of Disaster and Emergency Health and Head of International Affairs Office in the School of Public Health and Safety, Iran. She participated in COP22 in 2016 and has worked on gendered experiences of disaster-affected people, conducting research projects on aspects of gender and disasters in Iran.

Dr Debra Parkinson is a social researcher, committed to feminism and social justice. She is an Adjunct Research Fellow with Monash University Disaster Resilience Initiative and Manager of Gender and Disaster Australia. 